\title{
Augusto y la Hispania Ulterior
}

\author{
Julián GonzÁlez FERnÁndez \\ Universidad de Sevilla \\ julgonzalez@us.es
}

\section{RESUMEN}

El autor manifiesta su opinión de que el año 40 a.C., fecha del tratado de Brindisi, la provincia de la Hispania Ulterior se dividía en dos zonas bien diferenciadas: el valle del Betis, profundamente romanizada, y el Norte del Guadiana, que continuaba siendo una tierra de conquista. El territorio hasta el Duero y su posterior romanización será debida íntegramente a Augusto, quien con posterioridad la dividirá en Bética y Lusitania, fijando los límites de ésta en el río Duero, sin que la Gallaecia haya pertenecido nunca a la misma, según se desprende del estudio de las fuentes literarias y del bronce de Bembibre, con su explícita mención de la provincia Transduriana.

Palabras clave: romanización. Bética. Lusitania. Gallaecia.

\section{Augustus and Hispania Ulterior}

\begin{abstract}
The author expresses his opinion that the year $40 \mathrm{BC}$, the date of the treaty of Brindisi, the province of Hispania Ulterior was divided into two distinct areas: the valley of Betis, deeply romanized, and Guadiana North, which remained a land of conquest. The control of territory up to the Douro and its subsequent Romanization will be due entirely to Augustus, who at an undetermined date divided it in Baetica and Lusitania, setting the limits of this in the Douro river. Gallaecia never belonged to it, as it is clear from the study of the literary sources and the bronze of Bembibre, with its explicit mention of the Transduriana provincia.
\end{abstract}

Key Words: Romanization, Baetica. Lusitania. Gallaecia. 


\section{Introducción}

Cuando Octavio asume el control y la administración de la Hispania Ulterior el año 40 a.C. en virtud del tratado de Brindisi, la situación de la provincia era compleja, con dos zonas bien diferenciadas en su grado de romanización, al Sur, la futura Baetica, de gran tradición urbana, con un elevado desarrollo económico y nivel cultural, y al Norte del Guadiana, la nueva Lusitania continuaba siendo todavía una tierra de conquista. El alto grado de desarrollo urbano de la Turdetania tiene un claro reflejo en el relato de los acontecimientos bélicos que tuvieron lugar en la Ulterior en la guerra civil entre César y Pompeyo, donde se mencionan numerosas ciudades amuralladas: Corduba, Carmo, Italica, Urso, Ategua, Munda, Hispalis, etc., incluso algunas dotadas de teatros, foros, pórticos, puertos con importantes astilleros, etc. (bell. civ. 2.18-20).

Por el contrario, que las tierras al Norte del Guadiana eran todavía tierra de conquista lo confirma el hecho de que pocos años antes se realizaron nuevas campañas militares contra los lusitanos, refugiados al norte del Tajo, en el Mons Herminius (Sierra de la Estrella), primero por César en el año 61 a.C., en su calidad de procónsul de la Ulterior, y años más tarde, en el 48 a.C., por el tribuno de la plebe Cassius Longinus, dejado por César como legado de la misma. Incluso en la guerra habida entre César y los hijos de Pompeyo el 45 a.C. las fuentes recogen la intervención de guerreros lusitanos, primero en la defensa de la Hispalis pompeyana, y, posteriormente, en la muerte del almirante cesariano Didius en las inmediaciones de Carteia (bell. Hisp. 35; 40).

Sin embargo la promoción jurídica de los turdetanos con la transición de los núcleos urbanos indígenas a la condición de colonias y municipios, a pesar de mostrar ya una plena asimilación de las instituciones políticas y religiosas de Roma, se vio frenada a lo largo de la primera mitad del siglo I a.C. por la fuerte oposición de los optimates a extender el sistema de colonias civium Romanorum con la consiguiente utilización del ager provincialis fuera del marco de la Península italiana. A otras razones de tipo institucional, debemos añadir también la conciencia de que la fundación de colonias, al convertirse el deductor en patrono y sus habitantes en clientes, contribuía al desarrollo de las clientelas provinciales, que podían convertirse en un claro elemento desestabilizador. ${ }^{1}$ Ni siquiera César consiguió superar durante su primer consulado en el 59 a.C. la oposición de los optimates a la lex Iulia agraria y la lex Iulia agraria Campana, que incluían el ager campanus y el stellatis y permitieron el asentamiento de veteranos de Pompeyo y de elementos de la plebe, en número incierto, pero cercano a los $50.000,{ }^{2}$ pero tampoco en este caso se hizo uso del ager provincialis. ${ }^{3}$

\footnotetext{
1 RoldÁn 1985, 39; MARÍN DíAZ 1988, 114.

2 BRUnt 1971, 313-315.

3 Marín DíAz 1988, 193-195.
} 
La colonización a lo largo de este período se caracteriza porque o bien determinados gobernadores provinciales proceden a la fundación de núcleos urbanos ${ }^{4}$ cuyo status jurídico será o no determinado con posterioridad por el Senado, o bien es el propio Senado el que concede a algunas ciudades indígenas el status de ciudad privilegiada. Lo único que podemos constatar es la existencia de un proceso de una importancia relativa en el que determinados gobernadores provinciales proceden a la fundación de núcleos urbanos, sin que tengamos constancia de que el Senado les haya concedido la condición de colonia o municipio, por lo que en ausencia de dicha confirmación hemos de seguir considerando dichas comunidades como peregrinas, ${ }^{5}$ con excepción de Carteia, que es la única cuya condición de colonia latina está atestiguada en Livio (43.3.1-4) ya en el año 171 a.C. Las demás, con excepción de Brutobriga ${ }^{6}$ alcanzarán muy probablemente su condición de ciudades privilegiadas gracias a la labor fundacional de César o Augusto.

\section{La Ulterior entre el 49 a.C. y la muerte de César}

Es bien sabido que la dictadura de César marcó un importante hiato en la política tradicional mantenida por el Senado de Roma a lo largo de la crisis republicana, y ello no sólo por el número de sus colonias, sino también por su ubicación en las provincias. ${ }^{7}$ El fundamento legal, y por ende el posible punto de partida de su actividad colonial, se basaba en los poderes que, en su calidad de dictador, le conferían las leges Aemilia de dictatore creando del 49 a.C. y la lex de dictatore creando del 48 a.C. y en las diversas disposiciones que culminaron con su nombramiento como dictador perpetuo. En virtud de su capacidad legislativa, César concede a finales del 49 a.C. a las ciudades de la Galia Narbonense el ius Latii y el título de colonias latinas, según el modelo de la Transpadana. Simultáneamente convierte las colonias latinas de la Cisalpina en municipios civium Romanorum, con lo que se concluye la integración total de la Península italiana en la constitución romana.

4 Concretamente se consideran ciudades fundadas en la Ulterior por los generales romanos: Italica (206 a.C. Escipión el Africano), Iliturgi (Ti. Sempronio Graco, 178/79 a,C.), Corduba (Marcelo el 152/151 a.C.), Brutobriga (D. Junio Bruto el 138/133 a.C.) y Metellinum (Quinto Cecilio Metelo el 80/79 a.C.)

5 No obstante, recientemente CANTO 1999, 145-191 y GARCía Fernández 2001, 79 defienden que la mayoría habrían sido colonias latinas desde el mismo momento de su fundación.

6 Brutobriga tan sólo nos es conocida por una acuñación monetal en cuyo anverso se lee T. Manlius T.f. Sergia y tal vez se refiera a ella Estéfano de Bizancio al mencionar una ciudad llamada Broutobría localizada entre el río Betis y el territorio de los turdetanos. Su fundación parece estar en relación con la actividad desarrollada en la Hispania Ulterior por D. Iunius Brutus entre el 138/133 a.C., y en ella se asentarían lusitanos supervivientes del ejército de Viriato (MARCo Simón ET ALII 2004, 232-233). Su localización se desconoce (ToVAR 1974, 171). Probablemente sería una ciudad peregrina (GALSTERER 1971, 15; WiEGELS 1975, 212; MARíN DíAz 1988, 135), aunque no falten voces que la consideran un municipio latino, cuya fecha de fundación sería el 42 a.C. (Grant 1940, 381).

7 BRUNT 1971, 239: "It is agreed that Caesar was much more ready than Roman statesmen has been to enfranchise provincials". 
Sin embargo, la información de que disponemos nos lleva a pensar que la latinización de la Ulterior debía esperar aún algunos años. En efecto, después de su triunfo en Hispania sobre los legados de Pompeyo en el otoño del 49 a.C., César celebra una asamblea en Corduba, y allí pronuncia un discurso, en el que da las gracias a los habitantes de la Ulterior, exime a ciudadanos romanos del pago de ciertos impuestos y devuelve los bienes confiscados por Varrón (bell. civ. 2.21). Nada en sus palabras, ni siquiera la expresión tributis quibusdam publicis privatisque praemiis "concedió algunos beneficios públicos y privados", nos permite deducir que entre tales beneficios se incluyese el cambio de status de alguna comunidad indígena, sino tan sólo parecen indicar la concesión de ciertas exenciones fiscales a ciudades y recompensas personales a algunos cives romani. Tan sólo tenemos noticias de la concesión a los gaditanos de la ciudadanía (Liv., per. 110,1: Gaditanis civitatem dedit ${ }^{8}$ Dio, 41.24.1-2: politeivan). Para la práctica totalidad de los estudiosos estas frases implican que César concedería a Gades el estatuto de municipium civium Romanorum, ${ }^{9}$ que la mención del quattuorvirato en el 43 a.C. (Cic., ad fam. 10.32.2) confirmaría plenamente. ${ }^{10}$

$\mathrm{Si}$ en el discurso pronunciado en Corduba al final de la campaña del 49 a.C. César, agradecido, concede beneficios a individuos y comunidades, al finalizar la campaña contra los hijos de Pompeyo, el 45 a.C., en otro pronunciado en Hispalis, se muestra lleno de cólera y resentimiento contra la provincia por su apoyo a la causa pompeyana, recordándoles su falta de lealtad por los favores y beneficios que siempre le había prestado ya desde su quaestura (bell. Hisp. 42). Este discurso, claro presagio de represalias sobre las ciudades que se le habían enfrentado, vendrá a ser su programa de actuación en la Ulterior. Será Dión Casio (43.39.4-5) quien de nuevo nos aclare cuáles fueron las bases de dicho programa: por un lado, un aumento desmedido de los impuestos, hasta el punto de apropiarse de las ofrendas realizadas al templo de Hércules Gaditano, confiscación de tierras a algunas ciudades y un tributo adicional a otras, y por otro, la concesión de tierras y exención de impuestos a los que le habían sido favorables, a algunos la politeia, y a otros la condición de colonos romanos.

¿Cómo hay que entender el término politeia? Tradicionalmente se ha traducido por civitas Romana e, incluso, como ya hemos señalado, se ha interpretado como la concesión del status de municipium civium Romanorum. Ahora bien, si aceptamos esta interpretación César quedaría excluido de la latinización de la Ulterior atestiguada por los 30 oppida Latio antiquitus donata de Plinio y las palabras de Estrabón (3.2.15), cuando dice que los turdetanos que viven cerca del río Betis se han adaptado tan completamente a la forma de vida romana que han olvidado su propia lengua y la

\footnotetext{
8 Sin duda convendría señalar que el vocablo civitatem nos ha sido transmitido no directamente de la obra de Livio, sino de una periocha, sobre cuyos resúmenes existen serias dudas de rigor y exactitud

9 HÜBner RE 7.439; Vittinghoff 1951, 33; BlázQuez 1962, 74; Galsterer 1971, 18; RodríGuez NeILA 1980, 50-55; MARÍn DíAz 1988, 215.

10 Sin entrar ahora en polémica, por no ser ese el objeto de esta ponencia, creemos que la referencia de Plinio a Gades como oppidum civium Romanorum, qui appellantur Augustani, Vrbe Iulia Gaditana, junto con las monedas en las que se señala a Agripa como parens et patronus municipii, resulta, cuando menos, perturbadora en una ciudad que era ya municipio romano en el 49 a.C. y merecería un análisis más profundo del realizado hasta ahora. Desgraciadamente no poseemos ninguna inscripción republicana en la que conste la tribu de ese período, aunque sí una moneda donde figura la leyenda COL. A. GAD (GARCíA-BELLIDo 1988, 324-335).
} 
mayoría de ellos han llegado a ser latinos (i.e han recibido el ius Latii), han acogido a colonos romanos, de modo que no están lejos de ser todos ellos romanos. Es decir, con tal exclusión todas estas ciudades deberían su status de ciudad privilegiada en exclusiva, a la actividad legislativa de Augusto. Por todo ello, la concesión de la politeia ha de entenderse, en mi opinión, no sólo como sinónimo de la civitas Romana, sino también del Latium y referirse a la promoción de determinadas comunidades al status de colonias o municipios latinos. ${ }^{11}$

Es más que probable que César no pudiese ejecutar personalmente sus planes de fundación de colonias y concesión del ius Latii en el corto período que media entre su regreso a Roma después de la batalla de Munda y su inesperada muerte: septiembre 45/marzo 44. Esta suposición parece confirmarse cuando en abril del 44 a.C., después de los idus de marzo, se aprobaron dos leyes, propuestas por Marco Antonio, la lex Antonia de actis Caesaris confirmandis y la lex Antonia de colonis deducendis, ${ }^{12}$ que tendían a ejecutar la política planificada por César y que permitían la fundación de nuevas colonias. Es evidente que con estas disposiciones Antonio pretendía ganarse la voluntad del pueblo y el apoyo de los veteranos de César con los que contaba para sus ambiciosos proyectos personales. Un ejemplo bien conocido de aplicación de esta última ley lo constituye la fundación de la colonia Iulia Genitiva, cuya deductio, fechada en el año 44 a.C. fue realizada en virtud de una lex Antonia ${ }^{13}$ iussu Caesaris, ${ }^{14}$ y nos revela con nitidez que la última voluntad de César fue ejecutada con presteza por Antonio.

Además de Urso las otras ciudades que fueron castigadas por su apoyo a la causa pompeyana con la confiscación de sus tierras y el asentamiento de colonos romanos

11 Sherwin-White 1973, 232, se preguntaba ya si se trata solamente de una referencia a la ciudadanía romana o debemos incluir también el ius Latii. Una vacilación semejante encontramos en Estrabón, que aplica indistintamente el vocablo Romaioi para referirse a romanos e itálicos (BRUNT 1971, 215-216).

12 Rotondi 1966, 417-418, 429.

13 Lex Vrs., cap. 104: lege Antonia senatusque consultis plebisque scitis ager datus atsignatus erit, probablemente se trate de la lex Antonia agraria del 44 a.C.; cap. 106: iussu C. Caesaris dictatoris deducta est. Cfr. Rotondi 1966, 433.

14 Las palabras de Plinio (3.12), al denominarla Vrso quae Genetiva urbanorum, parecen indicar que los colonos de la misma procederían de la plebs urbana de Roma y confirmaría así el conocido pasaje de Suetonio (Caes. 42.1) que alude al asentamiento en colonias transmarinas de 80.000 ciudadanos romanos. Sin embargo, el apelativo urbanorum solo está testimoniado en Plinio y en la lex de la colonia se la denomina colonia Iulia Genetiva, por lo que tal vez el apelativo pliniano haga referencia a que los colonos asentados formaran parte de una legión urbana, como, por ej. la legio $V$. Además, el concepto transmarinae provinciae se emplea normalmente para designar las provincias situadas al otro lado del Adriático, es decir, Egipto, Asia, Siria, etc., por lo que sin duda Suetonio no se está refiriendo a las provincias occidentales. Por otra parte, el testimonio de una inscripción ursaonense en la que se menciona a un centurión de la legión XXX, C. Vettius C.f. Ser. (CIL II, $1404=I L S 2233=$ = CILA II, 3.620) apunta más bien hacia una colonia militar de César. Conocemos la permanencia en Hispania de esa unidad, reclutada en Italia el año 49 a.C., que se encontraba en Hispania el 48 a.C. a las órdenes de Q. Cassius Longinus y en el 44/43 a.C. al mando de Asinius Pollio (bell. Alex. 53.5; Cic., ad fam. X $31.5 ; 32.4$ ). Con estos datos podemos fechar la inscripción en el periodo triunviral, es decir, una quincena de años después de la fundación de la colonia y todo parece indicar que un contingente de la legio $X X X$ participó en la fundación de la colonia Genetiva Iulia (Le Roux 1982, 50-51), incluso se ha llegado a pensar que $C$. Vettius habría sido nombrado duoviro directamente por el propio César (HARDY 2005, 8). 
fueron Hispalis colonia Romula, Hasta Regia y Corduba colonia Patricia. ${ }^{15} \mathrm{Al}$ tratarse de un plan definido y global debemos entender que todas ellas serían fundadas al mismo tiempo que la colonia Iulia Genetiva o en una fecha muy cercana. Todas ellas fueron inscritas en la tribu Sergia, que ya había sido utilizada en la fundación republicana de Carteia. Estas cuatro serán, en mi opinión, las únicas colonias, cuya fundación podemos atribuir con seguridad a los proyectos del dictador.

El gran mérito de César fue romper la oposición del Senado al establecimiento de colonias en el ager provincialis como paso necesario para la integración de las comunidades indígenas, a través de un proceso de urbanización de las ciudades existentes y creación de otras nuevas, orientado a una mejor administración de las provincias. ${ }^{16}$ No obstante, la actuación de César no se puede considerar revolucionaria, pues las comunidades de la Ulterior tenían ya un alto grado de romanización, que les facilitaba el acceso al status de ciudad privilegiada. Podemos, pues, afirmar que actuó de forma prudente en la concesión de la civitas Romana o el Latium, al seguir el modelo

15 Corduba es otra ciudad cuya fecha de fundación y status ha hecho correr ríos de tinta (MeLCHOR ET ALII 2005; VAquerizo - Murillo ET ALII 2011, 9-46). La única referencia explícita sobre Corduba nos la ofrece Estrabón (3.2.1), cuando dice que "Corduba fue fundación de Marcelo" y que "ya desde su origen fue habitada por gente escogida, romanos e indígenas, y fue la primera colonia que los romanos enviaron alli". Dos son las fechas posibles de la fundación de Corduba, el 169/168 a.C., cuando Marcelo dirigió como pretor las dos provincias hispanas, y el 152/151 a.C., cuando, en calidad de cónsul, desempeñó el cargo de gobernador de la Citerior. Aunque la primera no deja de tener sus defensores (Blanco 1966, 19-20; Castillo 1974, 191; Chaves 1977, 19; Knapp 1977, 10; IBAÑEz CASTro 1983, 59), parece más probable la segunda (HüBNER, CIL II, p. 306; Vittinghoff 1951, 72; García y Bellido 1959, 451-452; Galsterer 1971, 9; Brunt 1971, 215; RODRÍGUEZ NeILA 1981, 110-111), pues sabemos que su actividad se centró en ambas provincias, y en la Ulterior combatió a los lusitanos a los que arrebató la ciudad de Nertobriga y se retiró posteriormente a Corduba donde invernó. No es menos problemático el carácter y status de la fundación. Algunos estudiosos consideran que Corduba tendría el status coloniae latinae ya desde el mismo momento de su fundación (HüBNER RE IV, 1222; Galsterer 1971, 9-10; Le Roux 1982, 35-36; KnapP 1983, 11). En cambio, la mayoría de los estudiosos rechazan que tuviese desde sus orígenes el status de ciudad privilegiada (VITTINGHOFF 1951, 72; García Y Bellido 1959, 452; Wilson 1966, 16-17; Brunt 1971, 215; Chaves 1977, 100; Rodríguez Neila 1981, 122; MARÍn DíAz 1988, 132-133). Además, para estos autores la mención en 48/47 a.C., de un conventus civium Romanorum implicaba que en estos momentos se trataba aún de una ciudad peregrina (Caes., bell. ciu. 2.19.3; bell Alex. 57,5; 58.4; 59.1. Marín DíAz 1988, 133, 206). También Rodríguez Neila ha puesto el énfasis en el hecho de que las expresiones ktísma Markéllou y prôthen apoikían no tienen por qué coincidir cronológicamente (Rodríguez Neila 1981, 112-114). También en apoyo de esta tesis, Wilson afirma que las cohortes colonicae mencionadas en las fuentes literarias (Caes., bell. ciu., 2.19.3) no sólo podían proceder de otras comunidades, sino que incluso dichos vocablos podían tener meramente un valor literario (WILSON 1966, $16 \mathrm{n}$. 8). Sin embargo, a la hora de fijar la fecha en que Córdoba alcanzó el status de colonia romana, atestiguado en Plinio (N.H. 3.10: Corduba colonia Patricia cognomine), las opiniones de estos estudiosos se orientan en tres direcciones: unos opinan que la deductio de la colonia se debería a los hijos de Pompeyo en 46/45 a.C., status que sería respetado por la clementia Caesaris y, con posterioridad, Augusto asentaría veteranos y le concedería el titulo de Patricia (HüBner CIL II, p. 306; Kornemann RE IV 527; Grant 1940, 4; García y Bellido 1959, 453); un segundo grupo se inclina por la autoría exclusiva de Augusto (Galsterer 1971, 10; BrunT 1971, 215). Por último, Knapp piensa que la deductio de la colonia Patricia podría deberse al propio César, opinión que consideramos acertada, y opina que el cognomen Patricia puede relacionarse con Liber Pater en cuya festividad, las Liberalia, César derrotó a los hijos de Pompeyo en la batalla de Munda (KNAPP 1983, 28). Nosotros pensamos que su adscripción a la tribu Sergia habla en favor de una fundación realizada por el propio dictador y, por consiguiente, descarta totalmente la tesis de que la deductio de la colonia fuese debida exclusivamente a Augusto. Por otra parte, la presencia de la tribu Galeria, implica necesariamente un segundo asentamiento, que, por el testimonio de las monedas, sabemos que eran veteranos de las legiones $\mathrm{V}$ y $\mathrm{X}$.

16 Keay 1988, 57; ID. 2003, 157; Curchin 1990, 7; AbasCal 1996, 281. 
traspadano de Pompeyo Estrabón, como paso preparatorio antes de la concesión de la plena ciudadanía. ${ }^{17}$ Pero, como bien dejó expresado Dión Casio "estas cosas no las hizo por nada", ya que, al mismo tiempo, buscaba ventajas políticas, económicas y sociales, ya que con el asentamiento de sus veteranos aumentaba su red clientelar, junto a un control estratégico de la Ulterior, siempre con el temor de nuevas convulsiones políticas. ${ }^{18}$

\section{Colonización de la Ulterior entre la muerte de César y el 15/13 a.C.}

Se ha señalado como una de las causas determinantes del inicio de las campañas de Augusto contra cántabros y astures en el 29 a.C. la necesidad de éste de contar con un éxito militar de suficiente resonancia y prestigio como medio de consolidar su nuevo papel de princeps. Esta necesidad le llevaría a elegir el frente del Norte peninsular como el más adecuado, por razones políticas y económicas, pero especialmente por su condición de límite occidental de la oikoumene. Cuando en el año 27 a.C. se extiende en Roma el rumor de una pronta intervención militar en Britania, la realidad era que Augusto preparaba la sumisión total de las dos Hispanias, ${ }^{19}$ pues es bien conocido que éste prefería la consolidación de las fronteras a la política expansionista de César, y además, provocaba cierta irritación en Roma que una pequeña porción de Hispania permaneciese fuera de su control después de casi 200 años de iniciada su conquista. ${ }^{20}$ Esta hipótesis estaría confirmada por la utilización que de estas campañas realizó la propaganda imperial en monedas, relieves, y, sobre todo, con la erección de altares en diversos lugares del nuevo territorio conquistado. ${ }^{21}$

Tal vez debamos incluir las guerras cántabras dentro de un ambicioso proyecto de Octavio, iniciado en los años treinta y dirigido a poner fin a la fase de tierra de conquista, que duraba ya más de un siglo y a llevar a cabo la pacificación definitiva de ambas provincias. Esta impresión se apoya en los sucesivos triunfos recogidos, ya desde el 39 a.C., en las listas de los Fasti Triumphales con la expresión ex Hispania, otorgados a todos los legados de Octavio en Hispania: Cn. Domicio Calvino (39-37 a.C.), C. Norbano Flaco (36-35), L. Marcio Filipo (34), y Apio Claudio Pulcro (33). Con excepción de Domicio Calvino, que lo hizo contra las tribus pirenaicas de los ceretanos, se desconoce la identidad de los indígenas contra los que lucharon estos legados, sin embargo, en el caso de Norbano Flaco todos los datos apuntan a campañas contra los pueblos situados al Norte del Guadiana.

$\mathrm{Su}$ presencia en la zona se apoya, por un lado, en su condición de deductor de la colonia Norba Caesarina en el 34 a.C., ${ }^{22}$ y por otro, en el triunfo que le fue decretado por el Senado al año siguiente. Se ha pensado, en razón del cognomen Caesarina,

17 Sherwin-White 1973, 232-233.

18 Bravo Bosch 2008, 109-110.

19 Номо 1949, 123-124.

20 SyMe 1934, 294; CROOK 1996, 163.

21 Roldán - WulfF 2001, 328, 333.

22 García y Bellido 1966, 280-284; Salas Martín 1982, 147-148; Sayas 1985, 61-75. 
de forma unánime que Norbano Flaco habría ejecutado un proyecto de César, sin embargo, sin necesidad de negar la existencia de tal proyecto, no es necesario, en mi opinión, recurrir a ese supuesto, pues la titularidad de la colonia se aclara perfectamente, si recordamos que el nombre de Octavio era, a partir de su adopción por César, C. Iulius Caesar, y no Octavio o Octaviano, como, por comodidad, se le viene llamando antes del 27 a.C. La tribu de Norba era la Sergia, la propia de las fundaciones republicanas.

Cabe preguntarnos si la deductio de esta colonia entre el Guadiana y el Tajo es un hecho aislado o se trata de una pieza dentro de un programa más sistemático. Es evidente que con ese paso hacia el Norte, Augusto tendía a fijar una línea defensiva al Sur del Tajo contra las incursiones de los lusitanos y sus vecinos los vetones, a cuyo fin sería necesario contar con más de un punto defensivo. A esta necesidad corresponden, en mi opinión, la fundación de las colonias Metellinensis, ${ }^{23}$ el antiguo praesidium de Metelo, sobre el río Guadiana, y de Scallabis Praesidium Iulium (Santarem) ${ }^{24}$ sobre el Tajo. Estas dos fundaciones se han atribuido a César, en base a la adscripción de ambas a la tribu Sergia, ${ }^{25}$ y al cognomen Iulium de la segunda, pero ninguno de estos argumentos resultan determinantes, pues, ya hemos visto que Norba está adscrita a la tribu Sergia, y, según veremos, las ciudades con cognomen doblado con el étnico Iulium son igualmente fundaciones de éste. Estas colonias, al estar constituidas por veteranos, constituían una importante reserva militar y controlaban los posibles movimientos de los lusitanos asentados al sur del Duero, donde ya habían sido atacados por César en el 61 y Casio Longino en el 48 a.C.

La fundación de estas colonias nos permite asumir que, después de las exitosas campañas militares de Norbano Flaco y los demás legados de Octavio, la zona al sur del río Duero había sido pacificada y sus habitantes aceptado el poder romano, paso previo para las campañas contra astures y cántabros, que iniciará poco después, en el 29 a.C., uno de los más brillantes generales de Octavio, T. Statilius Taurus. Esta suposición viene confirmada por el bronce de Bembibre con su referencia ambivalente a la provincia transduriana, entendida como actividad militar encomendada a los legados

23 Metellinum, su fundación se atribuye a Q. Cecilio Metelo en 80/79 (Henderson 1942, 7; García Y Bellido 1959, 458; BlÁzQuez 1962, 123; GALSTERER 1971, 14; SAlas 2001, 101-116) y es mencionada por Plinio (4.117) como (colonia) Metellinensis, por Ptolomeo (2.5.8) Kaikília Geméllinon ê Metellína, y en el It. Ant. (416.2) como Metellinum. Se identifica con la actual Medellín (Tovar 1974, 231). Su status sería en su origen en el una ciudad peregrina. La hipótesis de algunos estudiosos que pensaban se trataría de una colonia civium Romanorum de Metelo carece de fundamento y se opone a la política colonial romana de este periodo. Es preferible pensar en una deductio posterior que se vincula por algunos a la actividad de César (VITTINGHOFF 1951,77; García y Bellido 1959, 459) o Augusto (Henderson 1942, 7), opinión que consideramos acertada.

24 Ha sido considerado como un praesidium de César continuado por el dictador como colonia, a partir de la tribu Sergia y el cognomen Iulium (FARIA 1999, 43), sin embargo, no han faltado las voces que piensan que la colonia se habría fundado, según un proyecto de César, poco después de su muerte (MANTAs 1993, 487), e incluso que se habría producido una segunda deductio por Augusto, según el testimonio de la inscripción $C I L$ II, 326 donde se menciona la tribu Galeria (GonZÁLEz 1989, 140-141; CuRCHIN 1991, 123; MANTAS 1993, 486487; ARRUdA - Viegas 1999, 189-190; VIEGAS 2003, 17-18).

25 Sin embargo, en Magacela, un lugar no lejos de Medellín, se ha encontrado el epígrafe de un legionario de la IIII Macedonica, inscrito en la Galeria (GAmallo - Madruga 1994, 298 n. 11). 
de Augusto: la conquista y pacificación definitiva del Norte peninsular, pero también como territorio concreto fuera de los límites específicos de la provincia Ulterior.

Además de las siete colonias civium Romanorum ya mencionadas, Plinio nos informa de la existencia en la Ulterior de otras siete: Ucubi Claritas Iulia, Iptuci Virtus Iulia, ${ }^{26}$ Pax ${ }^{27}$ Iulia, Asido Caesarina, Augusta Emerita, Astigi Augusta Firma y Tucci Augusta Gemella, de las que las tres últimas muestran claramente que su deductio fue realizada por Augusto después del 27 a.C. La titularidad de las tres primeras muestra una estructura que se repite en diversas ciudades de la Ulterior: Concordia Iulia, Constantia Iulia, Valentia Iulia, Felicitas Iulia, Liberalitas Iulia, ${ }^{28}$ así como en tres colonias de Mauritania. ${ }^{29}$ No hay duda de que estos títulos constituyen el ideario diseñado por Octavio no sólo para realzar las cualidades de César, sino también las propias, en cuanto hijo y heredero del divus Iulius. Después de la derrota de Antonio en Actium se daban las circunstancias necesarias para conceder a las nuevas ciudades privilegiadas titularidades que divulgasen por todo el Orbe las grandes virtudes que adornaban el carácter del único dueño del poder en Roma, tal como queda reflejado en su nombre, Imp. Caesar Divi filius. ${ }^{30}$ Todas estas colonias, Pax Iulia, Ucubi Claritas Iulia, Iptuci Virtus Iulia, habrían sido fundadas por Octavio entre el 31 y el 27 a.C. Todas ellas estaban adscritas a la tribu Galeria, propia, como es bien sabido, de las fundaciones augusteas.

Todavía continúa siendo un tema de debate si el autor de la deductio de Asido Caesarina fue César ${ }^{31}$ o Augusto, ${ }^{32}$ e incluso si era una ciudad privilegiada antes de la misma. Una inscripción de Asido donde se menciona a unos municipes Caesarini y a un IIIIvir ha llevado a algunos estudiosos a considerar que Asido sería un municipio latino de César o de época triunviral. ${ }^{33}$ Sin embargo, ninguno de estos argumentos resultan probatorios, ya que el vocablo municipes puede significar ciudadano en un sentido general, sin indicar explícitamente su pertenencia a un municipio, pudiendo aplicarse por consiguiente a cives nacidos en una colonia para diferenciarse de los incolae o inquilini de la propia colonia,$^{34}$ y los IIIIviri están documentados en algunas colonias Romanas de Augusto continuadoras de antiguos municipios e, incluso, en colonias de éste ex novo. ${ }^{35} \mathrm{La}$ adscripción de sus magistrados a la tribu Galeria,

26 SAQUETE 2011, 167-186.

27 FARIA 2001, 351-352.

28 GALSTERER-KRÖLl 1975, 120-121, en un brillante trabajo llegó a la conclusión, que considero acertada, de que aquellas ciudades cuyos títulos aparecen doblados con el étnico Iulia/Iulium, Virtus Iulia, Concordia Iulia, Pax Iulia, etc. serían fundaciones de Octavio.

29 Gosalbez GRAVIOTO 2011, 249-272.

30 SiMPSON 1998, 419-437; FARIA 2001, 351-352.

31 Thouvenot 1973, 149; D’Ors 1974, 258.

32 Albertini 1923, 59-62; Henderson 1942, 13; VitTinghoff 1951, 104 n. 8; García y Belllido 1949, 476-477; Blázquez 1962, 75; Galsterer 1971, 20; Tovar 1974, 150; KNAPP 1977, 211; PAdilla Monge 1985, 325; GONZÁLEZ 2011, 279-281.

33 Van Nostrand 1916, 115; Vittinghoff 1951, 44, 108 n. 8; Galsterer 1971, 20; Padilla Monge 1985 , 312.

34 Arnold 1974, 243-244; D’Ors 1953, 140; Rodríguez Neila 1976, 165; Padilla Monge 1985, 312.

35 LAFFi 2002, 246-250. 
apunta, en mi opinión, claramente hacia una fundación de Augusto, cuya deductio, ante la ausencia del cognomen Augusta, habrá que situarla con anterioridad al 27 a.C.

Tres son las colonias fundadas por Augusto después del 27 a.C.: Augusta Emerita, fundada el 25 a.C. con veteranos de las legiones $V$ Alaudae y X Gemina, Astigi Augusta Firma, deducida probablemente en la misma fecha, por la coincidencia de la tribu Papiria, con veteranos de las legiones VI Victrix, IIII Macedonica y II Augusta (Pansiana) y finalmente Tucci Augusta Gemella, con veteranos de las legiones IIII Macedonica y X Gemina, todas ellas presentes en las guerras cántabro-astúricas.

La presencia perturbadora de la tribu Sergia en la colonia Augusta Gemella ha originado cierto debate, y así se ha llegado a suponer que los individuos inscritos en dicha tribu habrían recibido probablemente a título individual de manos de César la civitas Romana ${ }^{36}$ No obstante, sin descartar esta posibilidad, nos parece más acertado, según el testimonio de Norba Caesarina, pensar en una deductio de Augusto en los primeros años de su control de la Ulterior, tal vez en la misma época de la colonia lusitana, el año 34 a.C., seguida de un nuevo contingente de colonos, inscritos éstos en la tribu Galeria, según la tantas veces comentada dualidad tribal en las colonias Romanas. Si se acepta esta hipótesis, se nos plantea la pregunta de si podría ser este el origen del cognomen Gemella: la existencia de una doble colonia.

\section{Latinización de la Ulterior hasta la división de la provincia}

La primera concesión del Latium a una provincia, fuera del marco de la península italiana, fue el realizado en el 49 a.C. por César en la Galia Transalpina, cuyas civitates recibieron el status de colonias latinas, según el modelo transpadano. No es posible determinar que ese mismo año haya hecho lo mismo en la Ulterior por el apoyo recibido en su campaña contra Varrón, el legado de Pompeyo, a pesar de que las fuentes literarias nos hablan de la intensa latinización llevada a cabo por el propio César y Augusto. En efecto, Estrabón en el ya mencionado pasaje (3.2.15) dice que "la mayoría de ellos [los Turdetanos] han llegado a ser latinos (i.e han recibido el ius Latii)", y Plinio (N.H. 3.15; 4.117) en sus sipnosis de la Bética y la Lusitania menciona un total de 30 comunidades dotadas del Latio antiquitus donata o Latii antiqui. ${ }^{37}$ Pero Plinio, que, como es bien sabido, utiliza fuentes augusteas, tan sólo habla de oppida, sin referencia alguna a su condición de municipio o colonia, e, incluso, sólo nos da el nombre de siete de ellas (cuatro en la Bética: Carissa Aurelia, Laepia Regia, Ugia Castrum Iulium y Ugia Caesaris Salutariensis ${ }^{38}$ y 3 en Lusitania: Ebora Liberalitas Iulia, Myrtilis y Salacia Urbs Imperatoria), aunque nos ofrezca el nombre de una veintena de ellas provistas de cognomina: Segida Restituta Iulia, Iliturgi Forum Iu-

\footnotetext{
36 GonZÁLEZ RoMÁN 2011, 145.

37 También se podría añadir el testimonio de Dión Casio, si se admite como probable el doble significado que hemos atribuido en las líneas precedentes al concepto politeia: ciudadanía romana y/o latina.

38 Henderson 1942, 7; Galsterer-Kröll 1975, 125; GonZÁlez Román 1980, 109.
} 
lium, Osset Iulia Constantia, etc., que revelan su condición de ciudades privilegiadas, es decir, colonias o municipios. ${ }^{39}$

A esta falta de concreción de Plinio en la condición jurídica de las ciudades de la Bética se viene a sumar el hecho de que Augusto, interesado en realzar el status de las colonias Romanas, menospreció el uso de este título para comunidades que nunca habían sido formalmente colonizadas, aunque sus habitantes hubiesen llegado a ser latinos por la concesión del ius Latii, y las transformó en municipios o colonias de ciudadanos romanos ${ }^{40}$ según tenemos atestiguado en Carteia, con el cambio de la tribu Sergia a la Galeria, y un fragmento de inscripción donde se lee in munic [- - - ]. ${ }^{41}$ Sin embargo, a pesar de todas estas dificultades, podemos constatar la existencia de colonias latinas de César y Augusto mediante un análisis diacrónico: primero serán colonias y luego municipios a causa de las reformas augusteas, y, sobre todo, por la enorme dificultad que plantea aceptar que las fundaciones cesarianas no fuesen colonias, según el precedente de sus actuaciones en la Galia Narbonense y en Sicilia. ${ }^{42}$

La falta de referencias concretas no significa que carezcamos de indicios probatorios de su existencia, concretamente podemos citar los tres siguientes:

a) La titularidad de algunos oppida plinianos. Su análisis nos permite distinguir un primer grupo de ciudades, cuyos títulos (Carissa Aurelia, Nabrissa Veneria, Ilipa Ilia, Callenses Aeneanici, Fortunales Siarenses, etc.) se relacionan con la familia de César o la gens Iulia y cuya fundación habría que atribuir al dictador. Un segundo, en el que el cognomen Iulium aparece doblado con alguna virtud (Concordia Iulia, Constantia Iulia, Forum Iulium, Restituta Iulia, Praesidium Iulium, etc.), que ya hemos visto al tratar de las colonias, y cuya fundación sería augustea..$^{43}$

b) Existe un problema de concordancia en las relaciones de Plinio que, en mi opinión, no ha sido suficientemente valorado, así, por ejemplo, en una serie como Celeberrima [oppida]... Segida quae Augurina cognominatur, Ulia quae Fidentia, Urgao quae Alba, Ebora quae Cerialis... Artigi quod Iulienses, Vesci quod Faventia, el relativo femenino quae no puede concordar ni con oppidum, ni con municipium, y además el paralelismo con otra serie colonial, como Ituci quae Virtus Iulia, Ucubi quae Claritas Iulia, Urso quae Genetiva Urbanorum, me mueve a pensar que la concordancia se establece en ambas series con la condición de colonia.

c) Un tercer argumento nos lo puede proporcionar la ciudad de Iliturgi Forum Iulium, que ha sido considerada por algunos como una fundación republicana, debido a un epígrafe honorario ofrecido por el populus Iliturgitanus a Ti. Sempronio Graco, calificado de deductor ${ }^{44}$ y que ha sido identificado erróneamente, como veremos, con Ti. Sempronius Gracchus, gobernador de la Citerior en el año 178 a.C. Sin entrar a discutir

39 Henderson 1942, 1-5; Brunt 1971, 584-587; GAlSTERER-Kröll 1975, 120-122; Hoyos 1979, 439442; González Román 1980, 110; Marín DíAz 1988, 220. La autoría de estas fundaciones fue atribuida por Henderson a César, según el mencionado pasaje de Dión Casio. Esta tesis ha sido aceptada, aunque con reservas, por Vittinghoff, Galsterer, Hoyos y Marín Díaz, y rechazada por Brunt.

40 Salmon 1969, 125, 137.

41 WiEgELS 1974, 203-209; ID. 1985, 26-27.

42 Henderson 1942, 4-6.

43 GALSTERER-KRÖLl 1972, 68-75; ID. 1975, 120-130.

44 Cfr. Blanco-La Chica 960, 193-197; Galsterer 1971, 13; Wiegels 1985, 26. 
a fondo esta hipótesis, nos parece más adecuado considerar que el deductor honrado por el populus sea cualquier otro miembro de esta ilustre familia que hubiese recibido el encargo por parte de Augusto. Lo que sí es importante es la mención del fundador de una colonia, que en razón de su cognomen, Forum Iuli, hemos de fechar entre el 31 y el 27 a.C.

Ahora bien, aunque se acepta de forma generalizada el papel jugado por César y Augusto en la latinización de la Ulterior, el fijar al detalle el número y status de las fundaciones de cada uno de ellos resulta un problema sin solución por la falta de testimonios documentales. En un principio se recurrió para distinguir entre ellas a los cognomina de las ciudades privilegiadas. ${ }^{45}$ Sin embargo, Augusto, al igual que César, utiliza el título de Iulia antes del 27 a.C., a partir de cuya fecha emplea Iulia Augusta o simplemente Augusta. ${ }^{46}$ Por todo ello, hemos considerado más operativo tratar en un único apartado de la concesión del Latium por parte de César y Augusto.

Otro intento consistió en examinar la estructura de sus cognomina, pero aparte de los dos grupos ya mencionados, existe un buen número de ciudades, cuyos cognomina no tienen el cognomen Iulium (Segida Augurina, Ulia Fidentia, Ilipula Laus, Vesci Faventia, Ossigi Latonium), y cuya fundación no es posible atribuir con cierta seguridad ni a César ni a Augusto, aunque algunas de ellas, como Ulia Fidentia u Obulco Pontificiense, por su firme apoyo a la causa cesariana en las guerras civiles muy bien podrían haber recibido este título de manos del propio César. En cuanto al probable status de las mismas, las opiniones se dividen entre los que piensan que serían colonias latinas transformadas por Augusto municipios o colonias ciuium Romanorum, ${ }^{47}$ y los que creen que la concesión del ius Latii sería obra de Augusto y que la decisión de asimilar las comunidades provinciales a los municipios de Italia habría sido también obra de éste, pues las actividades municipales de César parecen limitadas a la Península italiana. ${ }^{48}$

Esta actividad legislativa realizada por Augusto, que se plasmó en la creación de municipios romanos y latinos en las provincias occidentales es bien conocida ${ }^{49}$ y de ella nos informan ampliamente las fuentes literarias; así, Dión Casio nos cuenta que en el 15 a.C. Augusto “colonizó numerosas ciudades en la Galia e Hispania”, y más adelante que "una vez finalizados todos los asuntos que le habían ocupado en las Galias, Germania e Hispania, habiendo gastado grandes sumas en unos distritos.... habiendo concedido la libertad y la ciudadanía a unos y arrebatándolas a otros, dejó a Druso en Germania y regresó a Roma el año 13 a.C." (Dión, 44.23.7; 25.1). También

45 Henderson 1942, 1-7; Vittinghoff 1951, 76-77; GAlsterer 1971, 65-66; Brunt 1971, 584-586; GALSTERER-KRÖLl 1972, 65-67; ID. 1975, 120-126; Hoyos 1979, 439-440; GonZÁlez RoMÁn 1980, 110-111; MARÍN DíAz 1988, 218-220.

46 GALSTERER-KRÖLl 1972, 68-72.

47 HENDERSON 1942, 4-6.

48 Kornemann RE 4.510-512; Henderson 1942, 1-7; Sherwin-White 1973, 232-235; Galsterer-KröLl 1975, 123-125. Galsterer, con su natural cautela, prefiere considerarlas simplemente como ciudades privilegiadas sin especificar su status. En esta misma línea se manifiestan, González Román y Marín Díaz (GALSTERER 1971, 65-66; GonzÁLEz RomÁn 1980, 110; MARín DíAz 1988, 221).

49 Sherwin-White 1973, 227-230. 
el propio Augusto afirma que en el año 13 a.C. volvió a Roma rebus in his prouinciis prospere gestis $(R G 12)$. Parece muy probable que estos asuntos felizmente solucionados entre el 15/13 a.C. fuesen una profunda reorganización del estatuto de las ciudades de Hispania y la Narbonense, un programa extenso y complejo de colonización y municipalización.

La sinopsis de la Lusitania nos ofrece el único ejemplo del nombre de sus ciudades privilegiadas, tres de las cuales tienen la misma estructura titular: Pax Iulia, Olisipo Felicitas Iulia y Ebora Liberalitas Iulia, cuya fundación el profesor Faria, con gran acierto, ha fechado entre el 31 y el 27 a.C., ${ }^{50}$ pero lo extraordinario es que cada una de ellas tiene un status distinto: colonia Romana, municipio Romano y municipio latino. ¿Cómo se explica que Augusto haya concedido a las tres ciudades al mismo tiempo diferente estatuto? No es posible dar una respuesta definitiva, pero, en mi opinión, esta diferenciación debe ser fruto de la evolución constitucional que ya hemos señalado: la transformación de colonias latinas en municipios romanos: Olisipo Felicitas Iulia, o latinos: Ebora Liberalitas Iulia. Por el contrario, Pax Iulia sería en su origen una colonia Romana, aunque no se puede descartar que hubiese sido también una fundación latina.

Un claro reflejo de aquel amplio programa legislativo que Augusto desarrollaría entre los años 15/13 a.C. lo constituye el hecho de que tan sólo conocemos diez ciudades adscritas a la tribu Sergia, en tanto que 76 (33 de la Bética, 6 de la Lusitania y 37 de la Tarraconense) lo están a la tribu Galeria, y serán, por consiguiente, o fundaciones augusteas ex novo o municipios procedentes de antiguas colonias latinas cesarianas. ${ }^{51}$

Ciertamente no es la primera vez que Roma acometió una empresa de tal envergadura, así ocurre, por ejemplo, en el 89 a.C. con la concesión de la ciudadanía Romana a los itálicos por la leges Iulia y Plautia Papiria, o la concesión del derecho latino a las ciudades de la Cisalpina por Pompeius Strabo. ${ }^{52}$ Un proyecto legislativo tan singular, que incluía la concesión del derecho latino y la constitución de numerosos municipios y colonias necesitaría sin duda un soporte legal, cuya necesidad se justifica por el hecho de que en las nuevas comunidades de derecho latino era necesario, por una parte, dar categoría de iudicia legitima a los litigios locales, y por otra, determinar qué personas y en qué circunstancias accedían a la civitas Romana per honorem. Sabemos que en época republicana las fundaciones de nuevas colonias o municipios se realizaban mediante una ley comicial, que en algunos casos podía contener reglas concretas sobre la constitución de las nuevas ciudades. Incluso cuando se trataba de la concesión de la ciudadanía romana o latina a una amplia base territorial o de la deductio de varias colonias de veteranos, las leyes particulares de estas colonias o municipios procedían de la adaptación de una ley-marco, válida para diversos mu-

\footnotetext{
50 FARIA 2001, 351-362.

51 WiEgELS 1985, 164-165.

52 Otras leyes que podríamos mencionar serían la lex Rupilia de iure siculorum del 131 a.C. y la lex Pompeia municipalis Bithyniae del 63 a.C.
} 
nicipios o colonias. Por ejemplo, los reglamentos de las 28 colonias de Augusto en Italia procedían de una ley-marco. ${ }^{53}$

Pienso que efectivamente Augusto extendió el procedimiento urbano a los municipios hispanos mediante una ley comicial: la lex Iulia municipalis, cuya existencia aparece confirmada de forma indirecta en la lex Irnitana a través de los siguientes argumentos: a) por la presencia determinante de la legislación augustea en la lex Irnitana; b) por el hecho de que la relación de fuentes legales, cuyo cumplimiento es preceptivo (capp. 19-20, 40, 81), se inicia con el divino Augusto (adversus leges plebis scita senatus consulta edicta decreta constitutiones divi Aug(usti) Ti(beri)ve Iuli Caesaris Aug(usti)...); c) por la falta de mención de la lex Papia Poppaea (9 a.C.) a propósito de los derechos concedidos por el ius liberorum (cap. B), y d) sobre todo, por las expresiones ante $h(a c)$ l(egem) rogatam, mencionada dos veces en la cap. 31, hac lege nihilum (minus) rogatur (capp. A y 79), y quacumque lege rogatione (cap. 91). ${ }^{54}$ Ya en mi comentario a la lex Irnitana defendía que la expresión ante hanc legem rogatam implicaba "the incorporation in our law, without proper re-phrasing, of a chapter of a general law on decuriones, passed in the comitia at Roma". ${ }^{55}$

En resumen, creo que, después de los datos anteriormente aportados, podemos considerar probados los siguientes puntos: 1) una extensión de los municipios de derecho latino a las provincias hispanas, realizada por Augusto en los años 15/13 a.C. durante su estancia en las mismas, de la que nos hablan las fuentes documentales, 2) la existencia de una ley comicial, a la que llamaremos lex Iulia municipalis, que sirviese para señalar los límites entre las jurisdicción local y la romana, la elección y atribuciones del ordo decurionum, de los magistrados, el acceso de éstos a la ciuitas Romana per honorem, etc., alguno de cuyos capítulos han sido reproducidos total o parcialmente en la nueva redacción de la ley Flavia municipal.

El enorme mérito de Augusto fue, no sólo, seguir el proyecto de romanización y latinización de César, sino ampliarlo y desarrollarlo en una escala como no se había conocido antes, ${ }^{56}$ hasta el punto de que en el corto espacio de tiempo de 25 años se pasó de cuatro colonias cesarianas, Carteia y tal vez alguna otra colonia latina, a 14 colonias y 11 municipios romanos y a 30 municipios latinos. Podemos, pues, afirmar que el proceso de romanización estaba en franco desarrollo en el Norte y Oeste, y concluido en la parte meridional, con lo que había llegado el momento de proceder a la división de la Ulterior y de poner la administración de la Ulterior Bética bajo la auctoritas del Senado.

53 GALSTERER 1987, 199.

54 GONZÁLEZ 1984, 23-32; ID. 1986, 150.

55 GonzÁLEz 1986, 208. Galsterer, (1988, 89 n. 60) que curiosamente ignora mi comentario anterior, piensa que algún copista ignorante, encontrada ante él la expresión POST H.L.D., leyese la D como R, y la desarrollase como $R$ (ogatam). Esta explicación carece de fundamento, pues en el texto ante el copista no figuraba la expresión POST H.L.D. sino ANTE H.L.ROGATAM, plenamente desarrollada. En realidad, Galsterer parece tomar la abreviación POST H.L.R. de la tabula Heracleensis, 11. 24, 160, y en su afán de demostrar que la ley de Irni no es una ley comicial, traslada mentalmente esta formulación a la lex Irnitana donde no figuraba. Además, ignora por completo las expresiones hac lege nihilum (minus) rogatur o rogatione, características de un ley comicial.

56 Sherwin-White 1973, 236. 
Aunque no tengamos una fecha precisa, todos los datos apuntan al 15/13 a.C. ${ }^{57}$ con motivo de la profunda reforma administrativa llevada a cabo por Augusto en las provincias occidentales, de las que nos hablan las fuentes documentales, según hemos ya expuesto. ${ }^{58} \mathrm{Se}$ considera de forma generalizada, de acuerdo a una referencia pliniana, que Gallaecia y Asturia quedarían incluidas en la Lusitania ${ }^{59}$ y que en una fecha posterior, entre 7/2 a.C., se incorporaron definitivamente a la Tarraconense. ${ }^{60}$ Sin embargo, Plinio lo que nos indica es que la Lusitania junto a (cum) la Gallaecia y Asturia, según Agripa, tiene unos límites definidos. Parece obvio que si ambas formasen parte de la misma, no sería necesario mencionarlas como entes independientes.

Podemos, pues, concluir, afirmando que el Principado de Octavio/Augusto significó el comienzo de un nuevo período en la Historia de Roma. La condición jurídica de los hispanos se vio favorecida con la creación no sólo de colonias y municipios romanos, sino también latinos, en los que los magistrados, junto con sus familias, accedían a la civitas romana per honorem. Por otra parte, con la fundación de colonias de veteranos, Augusto no sólo buscaba solucionar el problema surgido con la necesidad de conseguir tierras para los soldados licenciados después de las guerras civiles, sino asegurar con estos efectivos de fuerte formación militar los territorios hispanos, alejados de Roma, ante posibles revueltas de las tribus ya sometidas.

\section{Bibliografía}

Abascal, J. M. (1996): “Derecho latino y municipalización en Levante y Cataluña”, [en] Teoría y práctica del ordenamiento municipal en Hispania, Revisiones de Historia Antigua, II, Vitoria.

Albertini, E. (1923): Les divisions administratives de l'Espagne romaine, Paris.

ARnold, W. T. (1974): The Roman System of Provincial Administration to the accesion Constantine the Great, [Oxford, 1914], reimp. Chicago.

Arruda, A. M. - Viegas, C. (1999): “The Roman Temple of Scallabis (Santarém-Portugal”, Journal of Iberian Archaeology, 185-224.

Blanco, A. (1966): "Séneca y la Córdoba de su tiempo", [en] Actas del Congreso Internacional de Filologia II, Córdoba, 19-20.

Blanco, A. - La ChicA, A. G. (1960), “De situ Illiturgis”, AEArq. 33, 193-197.

Blázquez, J. M. (1962): "Estado de la romanización en Hispania bajo César y Augusto", Emerita 30, 74.

Bravo Bosch, Ma J. (2008): "La reorganización administrativa de Hispania con César y Augusto", RIDA 55, 107-137.

BRunt, P. A. (1971): Italian Manpower 225 B.C.-A.D. 14, Oxford.

\footnotetext{
57 Alföldy 1969, 224; Richardson 1998, 122-123; Crook 1996, 166.

58 Algunos autores, apoyándose en Dio 53.12.4-5, opinan que la división se realizaría en el 27 a.C.: ALBERTINI 1923, 36-38; Millar 1966, 163.

59 Nicols 1987, 130; Santos Yanguas 1985, 58; Bravo Bosch 2008, 126.

60 Plin. 4.118: Lusitaniam cum Asturia et Gallaecia patere longitudine DXL, latitudine DXXXVI, Agrippa prodidit
} 
CANTO, A. (1999): “Le Vetus Urbs de Itálica, quince años después. La planta hipodámica de D. Demetrio de los Ríos, y otras novedades", CuPAUAM 145-191.

Castillo, C. (1974): "Hispanos y romanos en Córdoba", Hispania Antiqua 4, 191-192.

Chaves, F. (1977): La Córdoba hispano-romana y sus monedas, Sevilla.

Crook, J. A. (1996): “Augustus: power, authority, achievement”, Cambridge Ancient History $10,163-164$.

Curchin, L. A. (1990): The Local Magistrates of Roman Spain, Toronto.

D'Ors, A.

(1953): Epigrafía Jurídica de la España romana, Madrid.

(1974): "La condición jurídica del suelo en las provincias de Hispania", [en] Atti del Convegno Internazionale sul tema: I diritti locali nelle province romane con particolare riguardo alle condizioni giuridiche del suolo, Accad. Naz. Linc., 371, 258-263.

FARIA, A. M.

(1999): “Colonizaçâo e municipalizaçâo nas provincias hispano-romanas: reanálise de alguns casos polémicos", Revista Portuguesa de Arqueologia 2.2, 29-51.

(2001): "Pax Iulia, Felicitas Iulia, Liberalitas Iulia", Revista Portuguesa de Arqueología 4/2, 351-362.

FERNÁNDEZ, F.

(1991): "Nuevos fragmentos de leyes municipales y otros bronces epigráficos de la Bética en el Museo Arqueológico de Sevilla", ZPE 86, 125-127.

(1971): Untersuchungen zum Römischen Städtewesen auf der Iberischen Halbinsel, Berlín.

(1987): “La loi municipale des Romains: chimère ou realité?”, RHD 65, 181-188.

(1988): "Municipium Flavium Irnitanum: a Latin Town in Spain”, JRS 78, 86-92.

GALSTERER-KRÖLL, B.

(1972): "Untersuchungen zu den Beinamen des Städte des Imperium Romanum”, EE 9, 65-67.

(1975): "Zu dem spanischen Städtelisten des Plinius", AEArq. 48, 120-126.

GARCÍA y Bellido, A.

(1959): "Las colonias romanas de Hispania", AHDE 29, 447-448.

(1966): “Consideraciones acerca de la fundación y evolución de la colonia Norba Caesari$n a$ ", BRAH 159, 279-291.

GarcíA-Bellido, Ma P. (1988): “Colonia Augusta Gaditana”, AEArq. 61, 324-335.

GARCíA FernáNDEZ, E. (2001): El municipio latino. Origen y desarrollo constitucional, Gerión Anejos, Madrid.

GonZÁlez, J.

(1984): "Italica, municipium iuris Latini", MC 20, 23-32.

(1986): "The lex Irnitana: a new copy of the Flavian municipal law", JRS 76, 47-243.

(1989): “Vrso: ¿tribu Sergia o Galeria?", [en] Estudios sobre Urso, colonia Iulia Genetiva, Sevilla, 133-140.

(1998): "Las fundaciones de Augusto y la tribu Galeria", [en] Actas del III Congreso Histórico-Arqueológico Hispano-Italiano (Toledo 1993), Madrid, 33-40.

(1995): "Reflexiones sobre la lex Flauia municipalis", SDHI 61, 810-818.

(1995a): "De nuevo en torno a la fundación de la colonia Astigi Augusta Firma", Habis 26, 281295. 
(2011): “Asido quae Caesarina”, [en] J. González - J. C. Saquete (eds.), Colonias de César y Augusto en la Andalucía Romana, Roma, 273-296.

González, J. - Saquete, J. C. (2011): Colonias de César y Augusto en la Andalucía Romana, Roma.

GonzÁlez Román, C.

(1980): Imperialismo y romanización en la provincia Hispania Ulterior, Granada.

(2011): “Colonia Augusta Gemella Tucci (Martos, Jaén)”, [en] J. González y J. C. Saquete (eds.), Colonias de César y Augusto en la Andalucía Romana, Roma. 129-166.

Gosalbez Cravioto, E. (2011): "Iulia Traducta y las colonias de Augusto en el norte de Marruecos", [en] J. González y J. C. Saquete (eds.), Colonias de César y Augusto en la Andalucía Romana, Roma, 249-272.

Grant, M. (1940): From Imperium to Auctoritas. A Historical Study of the Aes Coinage in the Roman Empire 49 B.C.-A.D. 14, Cambridge.

HARDy, E. G. (2005): Roman Laws and Charters, [Oxford, 1912], 2a ed. New Jersey.

Henderson, M. I. (1942): "Iulius Caesar and Latium in Spain”, JRS 32, 1-15.

Homo, L. (1949): Augusto, trad. esp., Barcelona, 123-124.

Hoyos, B. D. (1979): "Pliny the Elder's title Baetican Towns: Obscurities, Errors and Origins", Historia 28, 439-450.

IbáÑez Castro, A. (1983): Córdoba Hispano-romana, Córdoba.

KeAY, S. J. (1988): Roman Spain, London.

KNAPP, R.

(1977): Aspects of the Roman Experience in Iberia, 206-100 B.C., Valladolid.

(1983): Roman Córdoba, (Univ. Calif. Publ., Classical Studies 30), Berkeley-Los AngelesLondon.

LAFFI, U. (2002) : “Quattorviri iure dicundo in colonie romane”, [en] P.G. Michelotto (coord.), Studi di Antichita in memoria di Mario Attlio Levi, Quaderni di Acme 5,5, Milano.

LAmberti, F. (1993): Tabulae Irnitanae. Municipalità e 'ius Romanorum ', Nápoles.

Le Roux, P. (1982): l'Armée romaine et l'organisation des provinces ibérique d'Auguste à l'invasion de 409, Paris.

Magallo, J. L. - Madruga, J. V. (1994): "Nuevos epígrafes extremeños (Sur de Cáceres y Norte de Badajoz)", Gerión 12, 287-300.

Mantas, V. (1993): “As fundações coloniais no território português nos finais da República e os inícios do Império", Actas do II Congresso Peninsular de História Antiga (Coimbra 1990). Coimbra, 465-500.

Marco Simón, F. - Pino Polo, F. - Remesal Rodríguez, J. (2004): Vivir en tierra extraña: emigración e integración cultural en el mundo antiguo, Barcelona.

MARÍn DíAz, A. (1988): Emigración, colonización y municipalización en la Hispania republicana, Granada.

Melchor, E. - Mellado, J. - Rodríguez Neila, J. F. (eds.) (2005): Julio César y Corduba: tiempo y espacio en la campiña de Munda (49-45 a.C.), Córdoba.

MillaR, F. (1966): “The emperor, the senate and the provinces", JRS 56, 163-164.

NiCOLS, J. (1987): “The conquest and political organization in Iberian Galicia”, AJPh 108/1, 130-131. 
Padilla Monge, A.

(1985): “Asido Caesarina: constataciones acerca de su status”, Habis 16, 325-330.

(1989): “El epígrafe CIL II 1305”, Habis 20, 185-192.

Richardson, J. S. (1996): The Roman in Spain, Oxford.

Rodríguez NeILA, J. F.

(1976): “A propósito de la noción de municipio en el mundo romano", HAnt 6, 166-167.

(1980): El municipio romano de Gades, Cádiz.

(1981): "Introducción a la Corduba Romana en época republicana", [en] Córdoba, apuntes para su historia, Córdoba.

RoLDÁN, J. M. (1985): “Urbanización y municipalización, instrumentos de la política imperial romana: el caso de la Hispania republicana", [en] Centralismo y descentralización. Modelos y procesos históricos en Francia y España, Madrid.

Roldán, J. M. - WulfF, F. (2001): Citerior y Ulterior. Las provincias romanas de Hispania en la era republicana, Madrid.

Rotond, G. (1966): Leges publicae populi Romani, $2^{\mathrm{a}}$ ed., Heildesheim.

SALAS MARTín, J.

(1982): "Consideraciones acerca de la fundación y evolución de la colonia Norba Caesarina", Norba 3, 145-156.

(2001): "Fuentes antiguas para el estudio de la colonia Metellinensis", Norba 15, 101-116.

SAlmon, E. T. (1969): Roman Colonisation under the Republic, London.

SANTOS Yanguas, J. (1985): Comunidades indígenas y administración romana en el noroeste hispánico, Vitoria.

SAquete, J. C. (2011): “Claritas Iulia y Virtus Iulia. Dos colonias romanas en el valle medio del Baetis", [en] J. González y J. C. Saquete (eds.), Colonias de César y Augusto en la Andalucía romana, Roma, 167-186.

SAYAS, J. J. (1985): "El caso de Norba Caesarina y sus contributa Castra Servilia y Castra Caecilia”, Mélanges Casa Velázquez 21, 61-75.

Sherwin-White, A. N. (1973): The Roman Citizenship, $2^{\mathrm{a}}$ ed., Oxford.

Simpson, C. J. (1998): “Imp. Caesar Divi filius. His second imperatorial acclamation and the evolution of an allegedly 'exorbitant' name”, Athenaeum 86/2, 419-437.

Syme, R. (1934): “The Spanish War of Augustus (26-25 B.C.)”, AJPh 55/4, 294-296.

Thouvenot, R. (1973): Essai sur la province romain de Bétique, [Paris 1940], $2^{\mathrm{a}}$ ed., Paris.

Tovar, A. (1974): Iberische Ländeskunde, Zweiter Teil: Die Völker und die Städte des antiken Hispanien, Wiesbaden.

Van Nostrand, J. J. (1916): "The Reorganization of Spain by Augustus", Univ. Calif. Publ. In History IV.2, Berkeley.

Vaquerizo, D. - Murillo, J. F. - Garrigues, J. A. (2011): "Novedades de arqueología en Corduba, colonia Patricia", [en] González, J. - Saquete, J.C. (eds.), Colonias de César y Augusto en la Andalucía Romana, Roma, 9-46.

Viegas, C. (2003): A terra sigillata da Alcáçova de Santarém: cerámica, economía e comercio, Lisboa.

VitTinghoff, F. (1951): Römische Kolonisation und Bürgerrechts-politik unter Caesar und Augustus, Mainz. 
Watkins, T. H. (1979): “Roman Citizen colonies and Italian Right”, Latomus 164, 48-49.

WIEGELS, R.

(1974): “Zum Rechtsstatus von Carteia während des Prinzipats”, $M D A I(M$,$) 15, 203-211.$ (1985): Tribusinschriften in Hispanien, Berlín.

WiLson, A. J. N. (1966): Emigration from Italy in the Republican Age of Rome, Manchester. 